\title{
Diagnosing and treating COPD: understanding the challenges and finding solutions
}

This article was published in the following Dove Press journal:

International Journal of General Medicine

27 August 2011

Number of times this article has been viewed

\section{Len Fromer}

David Geffen School of Medicine at UCLA, Los Angeles, California, USA
Correspondence: Len Fromer David Geffen School of Medicine at UCLA, 15525 Hamner Drive, Los Angeles, CA 90077, USA

$\mathrm{Tel}+\mathrm{I} 3103838168$

Fax + I 310 47| 5392

Email mdwelby@aol.com
Abstract: Chronic obstructive pulmonary disease (COPD) is characterized by airflow obstruction that is not fully reversible; symptoms include chronic cough, sputum production, and dyspnea with exertion. An estimated $50 \%$ of the 24 million adults in the USA who have COPD are thought to be misdiagnosed or undiagnosed. Factors contributing to this include a low awareness of COPD and the initial symptoms of the disease among the general population, acceptance of these symptoms as a consequence of aging or smoking, some symptomatic similarity to asthma, and failure of health care personnel to use spirometry for diagnosis. Increased familiarization with COPD diagnosis and treatment guidelines, and proactive identification of patients with increased risk of developing COPD through occupational, environmental, or lifestyle exposures, will assist in a timely, accurate diagnosis and effective treatment, which will consequently improve patient outcomes. This review addresses the issues surrounding the diagnosis and misdiagnosis of COPD, their consequences, and how COPD can be better managed within primary care, including consideration of COPD care in patient-centered medical home and chronic care models.

Keywords: primary care, undiagnosed, misdiagnosed, chronic care model, patient-centered medical home

\section{Introduction: definition of COPD, disease impact on patients, and epidemiology}

Chronic obstructive pulmonary disease (COPD), which is characterized by partially reversible airflow obstruction, is primarily caused by exposure to cigarette smoke and other occupational and environmental pollutants; ${ }^{1}$ the widely used definitions of COPD are shown in Table 1.2-6 The most common symptoms of COPD include chronic cough, abnormal sputum production, and dyspnea with exertion. ${ }^{7}$ This disease further impacts patients through reduced lung function and reduced quality of life (QoL). ${ }^{8-10}$ The reduction in lung function is progressive and leads to exercise intolerance, a consequent reduction in activity as patients avoid the discomfort of breathing difficulties, and continued physical decline. ${ }^{11}$ As the disease advances, symptoms worsen, exacerbations increase in frequency and severity, and lung function is further compromised, causing a downward spiral of events until death eventually occurs (Figure 1). The patient's QoL, rate of decline, frequency of exacerbations, and emergency hospitalizations can all be influenced and improved by lifestyle interventions and pharmacologic treatment. ${ }^{3,4,12-14}$

Unfortunately, COPD is not a rare condition and an estimated 50\% of the 24 million adults in the USA who have COPD are thought to be misdiagnosed or undiagnosed. ${ }^{15}$ 
Table I Definitions of chronic obstructive pulmonary disease

\begin{tabular}{l} 
Organization \\
\hline American Thoraci \\
Society/European \\
Respiratory Society
\end{tabular}

$\left(\right.$ ATS/ERS) ${ }^{2}$

Canadian Thoracic Society $(\mathrm{CTS})^{3}$

Global Initiative for Chronic Obstructive Lung Disease (GOLD) ${ }^{4}$

National Institute for Health and Clinical Excellence (NICE) ${ }^{5}$

World Health Organization (WHO ${ }^{6}$

\section{Definition}

Chronic obstructive pulmonary disease (COPD) is a preventable and treatable disease state, characterized by airflow limitation that is not fully reversible. The airflow limitation is usually progressive and is associated with an abnormal inflammatory response of the lungs, to noxious particles or gases, primarily caused by cigarette smoking. Although COPD affects the lungs, it also produces significant systemic consequences. Chronic obstructive pulmonary disease (COPD) is a respiratory disorder largely caused by smoking, and is characterized by progressive, partially reversible airway obstruction and lung hyperinflation, systemic manifestations, and increasing frequency and severity of exacerbations. COPD is a preventable and treatable disease with some significant extrapulmonary effects that may contribute to the severity in individual patients. Its pulmonary component is characterized by airflow limitation that is not fully reversible. The airflow limitation is usually progressive and associated with an abnormal inflammatory response of the lung to noxious particles or gases. COPD is characterized by airflow obstruction. The airflow obstruction is usually progressive, not fully reversible and does not change markedly over several months. The disease is predominantly caused by smoking. Chronic obstructive pulmonary disease (COPD) is a lung disease characterized by chronic obstruction of lung airflow that interferes with normal breathing and is not fully reversible.

The aim of this review is to identify the issues surrounding the diagnosis and misdiagnosis of COPD, their consequences, and to address how this situation can be better managed in primary care.

\section{Methods}

Medline searches (using PubMed) were carried out using variations and combinations of the following keywords: COPD, undiagnosed, underdiagnosis, prevalence, treatment, patient-centered medical home (PCMH), and asthma. Bibliographies of articles were examined to identify further citations. All nonhuman studies and articles in languages other than English were excluded.

\section{Barriers to COPD diagnosis and treatment \\ Primary care practitioner- and practice-related barriers}

Lack of awareness and knowledge about COPD are major reasons why primary care practitioners (PCPs) and other health care providers may delay or incorrectly diagnose COPD. Results from a survey of American family physicians, nurse practitioners (NPs), and physician's assistants (PAs) $(\mathrm{n}=284)$ indicated that fewer than $50 \%$ of this test group reported knowledge or use of COPD diagnosis and treatment guidelines, ${ }^{16}$ suggesting that familiarity with diagnosis and treatment guidelines, and implementation of the recommendations, could be more widespread.

Often, recognition of COPD does not occur until the disease has progressed to moderate or severe stages, ${ }^{17-19}$ by which time patients' symptoms have worsened; they have a poor QoL and a rapidly declining condition. This trend toward late recognition of the disease may persist in spite of a growing body of scientific literature on COPD and updated disease guidelines (Table 2). ${ }^{2-5}$ Guidelines for COPD diagnosis (Table 2) ${ }^{2-5}$ have been developed to help PCPs recognize patients with symptoms and those at risk of developing COPD; therefore awareness of and adherence to these guidelines can help in the early diagnosis of COPD.

Some degree of therapeutic nihilism may also contribute to COPD remaining undiagnosed or undertreated. Data from a test group of 284 physicians, NPs, and PAs showed that only $15 \%$ of this group thought that treatment improved COPD symptoms, $13 \%$ thought longevity could be extended by COPD treatment, and 3\% thought that it reduced exacerbations or that pulmonary rehabilitation was useful. ${ }^{16}$

Obtaining an early diagnosis of COPD can be challenging for PCPs, as patients with mild COPD and a smoker's cough may experience little impact on breathing ability and no obvious additional abnormal symptoms. ${ }^{20}$ Although smoking is the major cause of COPD, risk factors also include exposure to occupational dusts and air pollution, repeated childhood respiratory infections, poor nutrition, and $\alpha 1$-antitrypsin deficiency; therefore, to focus solely on patients who smoke may also contribute to underdiagnosis of COPD. Individuals who are nonsmokers, but who are regularly exposed to secondhand smoke should also be considered at risk of COPD. A study by Bednarek et $\mathrm{al}^{21}$ indicates the importance of considering a diagnosis of COPD for nonsmokers and smokers alike, as detection of COPD in this study would have been reduced by $26 \%$ if a "smokers only" criterion had been applied. 


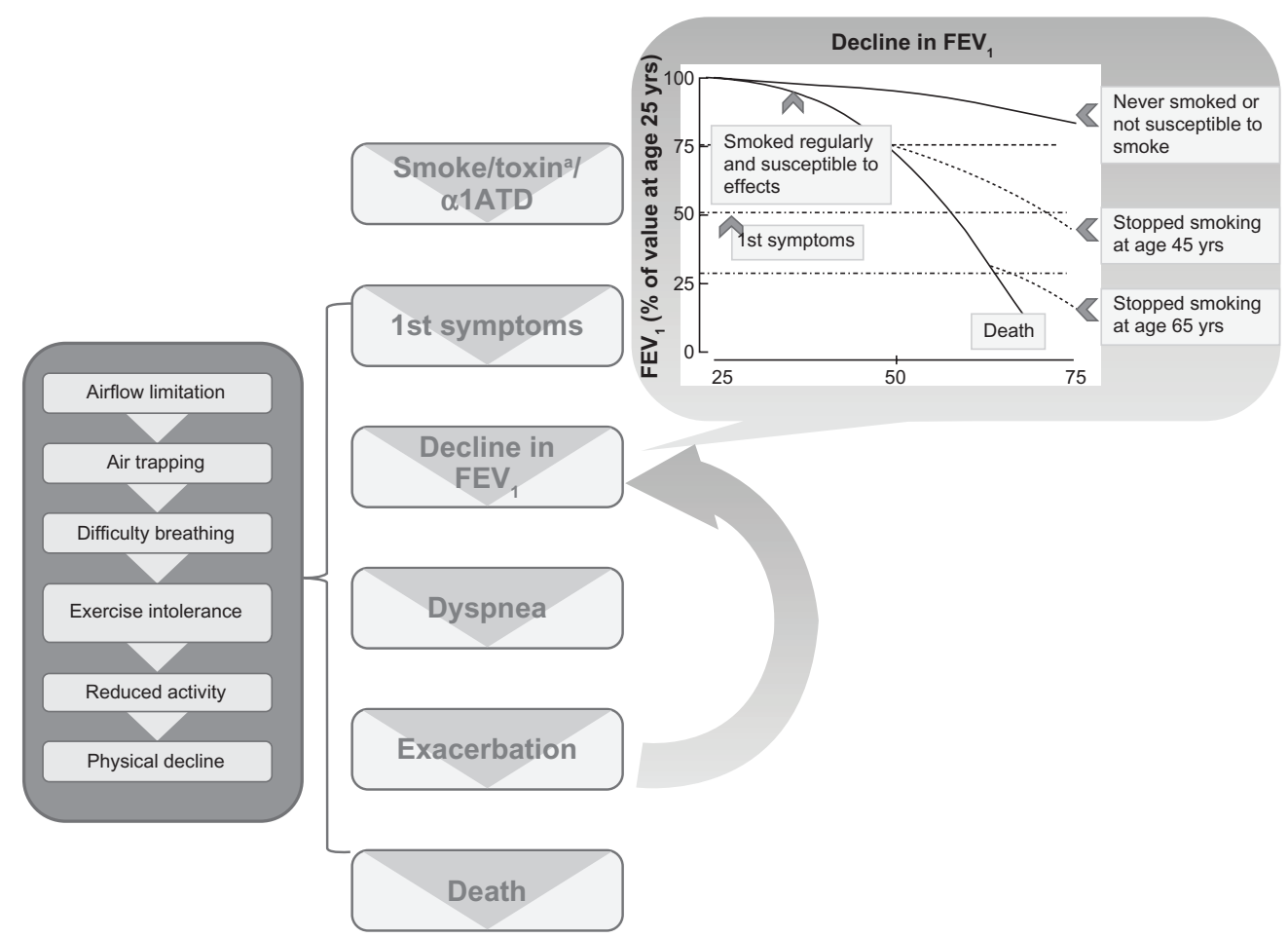

Figure I Disease course of chronic obstructive pulmonary disease.

Notes: The decline in forced expiratory volume in I second $\left(\mathrm{FEV}_{1}\right)$ graph is adapted from Fletcher and Peto, 1977. ${ }^{9}$ Reproduced from "The natural history of chronic airflow obstruction," British Medical Journal, C Fletcher, R Peto, Vol I, I645-1648, copyright 1977 with permission from BMJ Publishing Group Ltd. aRefers to an inhaled occupational/ environmental toxin.

Abbreviation: $\alpha$ IAHD, $\alpha$ I-antitrypsin deficiency.

Failure to use appropriate diagnostic tools could further contribute to under- or misdiagnosis..$^{22,23}$ Despite spirometry being a vital tool to establish a diagnosis of COPD, it is widely underutilized, even if available in a medical practice. ${ }^{24,25}$ A survey of 943 PCPs found that, although $64 \%$ of practices had access to spirometry, only $34 \%$ regularly used it. ${ }^{26}$ This situation does not appear to improve when the patient's disease state is severe enough to warrant hospitalization. A retrospective review of 553 patients, hospitalized with respiratory failure or undergoing ventilator support, with a follow-up period of up to 8 years, found that only $31 \%$ of these patients had their diagnosis confirmed by spirometry, despite having a clinical diagnosis of COPD. ${ }^{27}$ To address these deficiencies, adequate training of PCPs and their practice staff in spirometry use and data interpretation is warranted. ${ }^{25,28}$

Diagnosis of COPD can also be hampered by diagnostic confusion between asthma and COPD. ${ }^{29}$ When patients present with cough, shortness of breath, and diminished exercise tolerance, there is a bias toward diagnosing asthma, particularly in women. ${ }^{30}$ In a study of 597 patients, Tinkelman et $\mathrm{al}^{29}$ found misdiagnosis of asthma and COPD to be common (approximately $40 \%$ previously diagnosed with asthma had COPD). Financial factors may also influence the bias toward asthma diagnosis because, in the USA, there is often a "pay for performance" incentive for PCP diagnosis of asthma but there is not for COPD. This is in contrast with the situation in the UK, where incentives have been introduced to promote and improve diagnosis, management, and quality of care for patients with COPD and asthma. ${ }^{31,32}$ Early indications are that the introduction of these incentive programs is leading to improved quality of care, and that there has been an increase in the use of spirometry and subsequent diagnosis of COPD in the UK. ${ }^{32,33}$ In the instance of misdiagnosis of COPD as asthma, patients receive treatment that is incorrect, which consequently fails to address their symptoms adequately. ${ }^{31}$ This is highlighted by a study of 328 patients with assumed asthma that found that $34 \%$ of the patients, in fact, had COPD. ${ }^{34}$

\section{Patient-related barriers}

It is important to recognize that patients also display a lack of awareness of COPD: failing to identify symptoms at the start of disease, accepting breathlessness and reduced exercise tolerance as part of normal aging, or attributing cough and sputum to their smoking habit. Unconsciously, such patients 
Table 2 Comparison of guidelines for the diagnosis and treatment of chronic obstructive pulmonary disease

\begin{tabular}{|c|c|c|c|c|}
\hline Content & ATS/ERS & GOLD & NICE & CTS \\
\hline Pages & 222 & 113 & 54 & 28 \\
\hline Diagnosis/Disease staging & $\checkmark$ & $\checkmark$ & $\checkmark$ & $\checkmark$ \\
\hline Risk factors & $\checkmark$ & $\checkmark$ & & $\checkmark$ \\
\hline Natural history & $\checkmark$ & $\checkmark$ & & \\
\hline Pathology, pathogenesis, and pathophysiology & $\checkmark$ & $\checkmark$ & & $\checkmark$ \\
\hline How to test for COPD & $\checkmark$ & $\checkmark$ & & $\checkmark$ \\
\hline Stable COPD management & $\checkmark$ & $\checkmark$ & $\checkmark$ & $\checkmark$ \\
\hline Smoking cessation & $\checkmark$ & $\checkmark$ & $\checkmark$ & $\checkmark$ \\
\hline Pharmacotherapy & $\checkmark$ & $\checkmark$ & $\checkmark$ & $\checkmark$ \\
\hline Pulmonary rehabilitation & $\checkmark$ & $\checkmark$ & $\checkmark$ & $\checkmark$ \\
\hline Long-term $\mathrm{O}_{2}$ & $\checkmark$ & $\checkmark$ & $\checkmark$ & $\checkmark$ \\
\hline Nutrition & $\checkmark$ & $\checkmark$ & $\checkmark$ & \\
\hline Surgery & $\checkmark$ & $\checkmark$ & & $\checkmark$ \\
\hline Sleep & $\checkmark$ & & & \\
\hline Air travel & $\checkmark$ & & $\checkmark$ & \\
\hline Exacerbation & $\checkmark$ & $\checkmark$ & $\checkmark$ & $\checkmark$ \\
\hline Palliative care & $\checkmark$ & & $\checkmark$ & $\checkmark$ \\
\hline Integrated disease management & $\checkmark$ & $\checkmark$ & $\checkmark$ & \\
\hline Separate patient guide ( 80 pages) & $\begin{array}{l}\text { Answers series } \\
\text { of questions }\end{array}$ & & & \\
\hline Patient education & & $\checkmark$ & $\checkmark$ & $\checkmark$ \\
\hline Translating guideline in primary care & & $\checkmark$ & & $\begin{array}{l}8 \text { page summary } \\
\text { for primary care }\end{array}$ \\
\hline Follow-ups and monitoring & $\checkmark$ & $\checkmark$ & $\checkmark$ & $\checkmark$ \\
\hline Case scenarios & & & & $\checkmark$ \\
\hline
\end{tabular}

Abbreviations: ATS/ERS, American Thoracic Society/European Respiratory Society; GOLD, Global Initiative for Chronic Obstructive Lung Disease; NICE, National Institute for Health and Clinical Excellence; CTS, Canadian Thoracic Society; COPD, chronic obstructive pulmonary disease.

adapt their lifestyle to compensate for their deteriorating health, until they have progressed to a stage where they have substantial and irreversible loss of lung function, and the impact is so severe that patients consider seeking medical opinion and intervention. ${ }^{35,36}$

Evidence from the literature suggests that early diagnosis and appropriate early treatment are beneficial for patients in terms of reduction of symptoms and improvement in QoL. ${ }^{37,38}$ For example, smoking cessation, which is the most effective intervention for improving disease course and survival in the early stages of COPD, can be encouraged and appropriate therapies started while the patient still has relatively intact lungs. ${ }^{38-40}$ However, this therapeutic goal may prove elusive, as patients also avoid discussing their COPD symptoms with a PCP because they harbor guilt about their smoking history. ${ }^{41}$ Such patient concerns can be alleviated by careful discussion to increase their knowledge base, providing support in smoking cessation, and giving priority to COPD treatment, regardless of smoking status, ${ }^{42}$ similar to the unbiased, proactive treatment given to patients with cardiovascular disease, irrespective of their dietary habits. ${ }^{43}$ When PCPs take this type of positive action to give treatment early in the course of disease, patient prognosis and QoL can be improved. Despite receiving PCP support, some patients may not be successful in smoking cessation programs, but COPD treatment can still improve the patient's everyday QoL. 17,38,44

Overall, the ongoing gap between PCP-diagnosed and actual COPD cases clearly illustrates that there is room for improvement in the level of knowledge regarding this disease and current treatment practices; examples in the literature exemplify the positive impacts of guideline implementation and of identifying and addressing barriers to diagnosis. ${ }^{45}$

\section{Making changes in practice to improve the diagnosis and treatment of COPD \\ Diagnosis}

Comprehensive guidelines have been developed by expert teams to aid diagnosis and treatment of patients with COPD. The available guidelines include those from the American Thoracic Society/European Thoracic Society (ATS/ERS), ${ }^{2}$ the Global Initiative for Chronic Obstructive Lung Disease (GOLD), ${ }^{4}$ the National Institute for Health and Clinical Excellence (NICE) in the UK, ${ }^{5}$ and the Canadian Thoracic 
Society (CTS). ${ }^{3}$ These guidelines share the same treatment goals but differ in the extent of detail and some recommendations; the ATS/ERS and GOLD guidelines are the most comprehensive, while the CTS guidelines include examples of case management that may occur in everyday practice (Table 2). PCPs, PAs, and NPs should be aware of, and familiar with, the COPD guidelines to ensure an early diagnosis and optimum management of COPD.

Another step toward improving the diagnosis of COPD is to have strategies in place to identify patients who may be at risk. There are suggested strategies in the diagnosis and treatment guidelines: the GOLD guidelines recommend a COPD evaluation for patients $>40$ years old, with activity limitation, breathlessness, cough, and a history of smoking or occupational/environmental exposure, ${ }^{4}$ while a lower age of 35 years has been suggested by the "ABC of chronic obstructive pulmonary disease" $" 46$ for initiating evaluation of patients who have identified risks of developing COPD and are exhibiting preliminary symptoms.

Although the majority of patients with COPD have a smoking history (more than $50 \%$ of smokers will develop COPD), ${ }^{20}$ the respiratory symptoms of nonsmokers should also be evaluated for COPD diagnosis. ${ }^{47}$ If a nonsmoking patient has symptoms of cough, shortness of breath, diminished exercise tolerance, and expectoration, questioning by the PCP to establish whether occupational/environmental exposures could have caused the symptoms is recommended and, if these are ruled out, these individuals should be screened for $\alpha 1$-antitrypsin deficiency as a cause of COPD.

Currently, there are new screening initiatives under development and evaluation to identify patients at risk of developing COPD or who are already symptomatic. Such initiatives include a two-step lung function questionnaire ${ }^{48,49}$ and a three-step screening strategy, which includes the following steps: (1) assess symptoms with a questionnaire; (2) for those patients where Step 1 identifies a risk of COPD, a baseline spirometry test should be performed; and (3) if baseline spirometry shows an abnormality, perform postbronchodilator spirometry. To improve the early diagnosis of patients with COPD, both the two-step and three-step strategies have the potential to be implemented in everyday practice.

Once patients at risk of COPD have been identified, the next step is to follow up with the tools that can confirm diagnosis. It is important to ensure that there are NPs, respiratory therapists, PCPs, or specialists who can efficiently and successfully champion patient spirometry, which is as essential to respiratory practice as electrocardiography is to cardiovascular investigations. As an example of how frequently spirometry might actually be required in diagnosis on a daily basis, if a PCP saw 20 patients per day, who were representative of the population of the National Health and Nutrition Examination Survey (NHANES) III, five patients may have respiratory symptoms and a further three patients may have COPD. ${ }^{50}$ With decreasing costs for baseline spirometry and the possibility of reimbursement for primary care spirometry, ${ }^{51}$ the spirometer is becoming an affordable piece of equipment that will rapidly pay for itself, which will enable a wider uptake of this methodology.

\section{Differentiating COPD from asthma}

It is essential to differentiate COPD from asthma to ensure correct treatment choices and optimal patient outcomes; ${ }^{52}$ this can be facilitated by a good understanding of the differences between COPD and asthma. Both COPD and asthma are associated with inflammation and a reduced rate of pulmonary airflow, but they can be distinguished by their differing causes and inflammatory mechanisms. In COPD, irritants, such as smoke, activate lung epithelial cells to release chemotactic factors, which in turn activate pathways that cause elastin degradation, emphysema, mucus hypersecretion, and small airway fibrosis. ${ }^{53}$ In asthma, triggers cause immunoglobulin activation of mast cells and pathways leading to bronchoconstriction and inflammation. ${ }^{53}$

COPD and asthma can be differentiated by pre- and postbronchodilator spirometry because airway obstruction is only partially reversible in COPD, while it is fully reversible in asthma. ${ }^{54,55}$ There may also be differences between the symptoms and medical histories of patients with COPD and asthma. Often, patients with COPD are older than 35 years, have a history of smoking, and may suffer from a persistent, worsening, productive cough. In contrast, asthma can occur at any age but often starts in childhood or adolescence and is characterized by an intermittent dry cough and wheezing. The distinctions between COPD and asthma diagnosis and treatment are summarized in Tables 3 and 4. 3,4,56

Correct diagnosis and treatment can be further complicated in patients where asthma and COPD coexist $;{ }^{4}$ in a study of 597 patients with obstructive lung disease, almost $25 \%$ had both asthma and COPD. ${ }^{29}$ In such individuals, it is difficult to differentiate between the two diseases, so additional investigations such as chest X-rays may sometimes detect hyperinflation, flattening of diaphragm domes, and basilar markings in COPD, which would normally be absent in patients with asthma. ${ }^{57}$ Establishing the inflammatory cell profile in bronchoalveolar lavage fluid or sputum may also be used to identify COPD and asthma, as elevated levels of 
Table 3 Differential diagnosis of chronic obstructive pulmonary disease and asthma

\begin{tabular}{|c|c|c|c|c|}
\hline Diagnostic features & \multicolumn{2}{|l|}{ COPD } & \multicolumn{2}{|l|}{ Asthma } \\
\hline Onset age & \multicolumn{2}{|c|}{ Usually $>35$ years } & \multicolumn{2}{|c|}{$\begin{array}{l}\text { Typically during childhood/adolescence, but } \\
\text { can be any age }\end{array}$} \\
\hline Allergic hypersensitivity & \multicolumn{2}{|c|}{$\begin{array}{l}\text { Family/Personal history } \\
\text { rarely a factor }\end{array}$} & \multicolumn{2}{|c|}{ Usually family/personal history } \\
\hline Smoking history & \multicolumn{2}{|c|}{ Often $>20$ pack-years ${ }^{\mathrm{a}}$} & \multicolumn{2}{|c|}{ Possible but not necessarily } \\
\hline Symptom occurrence & \multicolumn{2}{|c|}{ Chronic and persistent } & \multicolumn{2}{|c|}{ Intermittent; usually symptom free } \\
\hline Cough & \multicolumn{2}{|c|}{ Persistent and productive } & \multicolumn{2}{|c|}{ Intermittent and nonproductive } \\
\hline Breathlessness & \multicolumn{2}{|c|}{ Progressive and persistent } & \multicolumn{2}{|c|}{ Intermittent and variable } \\
\hline Disease course & \multicolumn{2}{|c|}{ Progressive worsening } & \multicolumn{2}{|c|}{ Stable (with exacerbations) } \\
\hline Nocturnal symptoms & \multicolumn{2}{|c|}{ disease state } & \multicolumn{2}{|c|}{ Common } \\
\hline Cause of exacerbations & \multicolumn{2}{|c|}{$\begin{array}{l}\text { Bacterial/viral respiratory } \\
\text { tract infection }\end{array}$} & \multicolumn{2}{|c|}{ Allergens, cold air, or exercise } \\
\hline $\begin{array}{l}\text { Spirometry determined GOLD } \\
\text { COPD stage/asthma state }\end{array}$ & FEV $_{1}^{b}$ & FEV $_{1} /$ FVC & FEV $_{1}{ }^{b}$ & FEV $/$ IFVC \\
\hline Mild/intermittent & $\geq 80 \%$ & $<0.70$ & $>80 \%$ & Normal $^{c}$ \\
\hline Moderate/mild persistent & $50 \%-79 \%$ & $<0.70$ & $>80 \%$ & Normal $^{c}$ \\
\hline Severe/moderate persistent & $30 \%-49 \%$ & $<0.70$ & $60 \%-79 \%$ & $\begin{array}{l}\text { Reduction } \leq 5 \% \\
\text { of normal }\end{array}$ \\
\hline Very severe/severe persistent & $\begin{array}{l}<30 \% \text { or } \\
<50 \% \\
\text { with CRF }\end{array}$ & $<0.70$ & $<60 \%$ & $\begin{array}{l}\text { Reduction }>5 \% \\
\text { of normal }\end{array}$ \\
\hline Response to bronchodilators & $\begin{array}{l}\text { Variable, } \mathrm{P} \\
\text { but may sh }\end{array}$ & $\begin{array}{l}\text { ormalize } \\
\text { ent }\end{array}$ & $\begin{array}{l}\text { Rapid res } \\
\text { improve } \\
\text { improves }\end{array}$ & $\begin{array}{l}\text { may greatly } \\
A B\end{array}$ \\
\hline
\end{tabular}

Notes: aTotal number of pack-years is calculated = (number of cigarettes smoked per day $/ 20) \times$ number of years smoking $\left(\mathrm{O}^{\prime}\right.$ Donnell et al, $\left.2008^{3}\right)$; $\%$ of predicted value; ${ }^{c}$ normal FEV $/$ FVC values for patients aged 8-19 years $=85 \%, 20-39$ years $=80 \%, 40-59$ years $=75 \%$, and $60-80$ years $=70 \%$. $30,4,17,20,37,46,55$

Abbreviations: GOLD, Global Initiative for Chronic Obstructive Lung Disease; COPD, chronic obstructive pulmonary disease; FEV FVC, forced vital capacity; CRF, chronic respiratory failure; PFT, pulmonary function test; SAB, short-acting bronchodilator.

neutrophils are characteristic of COPD but not of asthma, and increased levels of eosinophils are characteristic of asthma but not of COPD. ${ }^{53,55,58}$

\section{Treating COPD}

Although not curable, COPD can be treated at any stage of the disease. ${ }^{3}$ The goals of COPD treatment are to relieve symptoms, prevent disease progression, improve exercise tolerance, improve QoL, prevent and treat exacerbations, and reduce mortality. ${ }^{4}$ The guidelines that provide information to assist diagnosis of COPD also have recommendations for patient treatment, which include strategies to minimize risk, lifestyle changes, and pharmacotherapy. ${ }^{2-5}$ The appropriate treatment depends on the patient, and should take into consideration factors such as their current exposure to lifestyle/ environmental/occupational risk factors and the severity of disease (Figure 2). If the patient is a current smoker at the time of diagnosis, support in smoking cessation should be given by the PCP, because it effectively reduces the rate of lung function decline. Providing vaccination against influenza to all patients with COPD, and against pneumonia to patients aged $\geq 65$ years and to those with forced expiratory volume in 1 second $\left(\mathrm{FEV}_{1}\right)<40 \%$ can also to help reduce the occurrence of exacerbations.

The pharmacologic treatment of COPD is centered on the use of bronchodilators ( $\beta-2$ agonists and anticholinergics) and inhaled corticosteroids. ${ }^{4}$ Depending on the severity of disease, the bronchodilators may be administered as required or as long-term maintenance therapy. ${ }^{4}$ Combination therapy with bronchodilators and inhaled corticosteroids is used to achieve effective bronchodilation as disease severity and pulmonary obstruction increase, with inhaled corticosteroids added to the treatment regime when a severe stage of disease is reached. ${ }^{4,59}$ Patients with severe COPD may also have hypoxemia and/or hypercapnia, which can be improved by the use of supplemental oxygen; this treatment can also lead to improvements in the patients' exercise capacity. ${ }^{60}$

These treatments are effective ways of meeting the goals of COPD management. A beneficial addition to pharmacotherapy is participation by the patient in pulmonary rehabilitation, which is recommended for all patients with 
Table 4 Differential treatment of chronic obstructive pulmonary disease and asthma

\begin{tabular}{|c|c|c|}
\hline Treatment & COPD & Asthma \\
\hline $\begin{array}{l}\text { Smoking } \\
\text { cessation }\end{array}$ & $\begin{array}{l}\text { Recommended, as } \\
\text { smoking accelerates } \\
\text { decline of lung function }\end{array}$ & $\begin{array}{l}\text { Recommended, as } \\
\text { smoking exacerbates } \\
\text { condition }\end{array}$ \\
\hline Air pollution & Avoid & Avoid \\
\hline Allergen & - & Avoid/Reduce \\
\hline $\begin{array}{l}\text { Influenza } \\
\text { vaccination }\end{array}$ & Recommended & Recommended \\
\hline $\mathrm{ICS}^{3,4,56}$ & $\begin{array}{l}\text { Not first-line therapy, } \\
\text { reserved for use in } \\
\text { severe/very severe } \\
\text { COPD in combination } \\
\text { with long-acting } \\
\text { bronchodilator }\end{array}$ & $\begin{array}{l}\text { Preferred therapy } \\
\text { for inflammation in } \\
\text { persistent asthma }\end{array}$ \\
\hline$\beta-2$ agonists & $\begin{array}{l}\text { Short-acting for } \\
\text { short-term therapy at } \\
\text { any disease state; long- } \\
\text { acting } \beta \text { - } 2 \text { agonists } \\
\text { recommended in } \\
\text { moderate and severe, } \\
\text { if short-acting } \beta-2 \\
\text { agonists not effective }\end{array}$ & $\begin{array}{l}\text { Recommended with } \\
\text { ICS, if asthma not } \\
\text { well controlled } \\
\text { with ICS alone }\end{array}$ \\
\hline Anticholinergics & $\begin{array}{l}\text { Short-acting and long- } \\
\text { acting anticholinergics } \\
\text { are recommended for } \\
\text { moderate to severe } \\
\text { COPD }\end{array}$ & $\begin{array}{l}\text { Can be an option if } \\
\beta-2 \text { agonists not well } \\
\text { tolerated, but variable } \\
\text { responses; not } \\
\text { indicated in the } \\
\text { USA for asthma }\end{array}$ \\
\hline Systemic steroids & $\begin{array}{l}\text { Used for exacerbation } \\
\text { treatment }\end{array}$ & $\begin{array}{l}\text { Used in severe asthma, } \\
\text { for exacerbation } \\
\text { treatment }\end{array}$ \\
\hline Theophylline & $\begin{array}{l}\text { Bronchodilators } \\
\text { preferred, due to } \\
\text { potential side effects } \\
\text { of theophylline }\end{array}$ & $\begin{array}{l}\text { Considered after } \\
\text { bronchodilators and } \\
\text { ICSs, due to potential } \\
\text { side effects of } \\
\text { theophylline }\end{array}$ \\
\hline Oxygen & $\begin{array}{l}\text { In advanced cases of } \\
\text { COPD, when oxygen } \\
\text { saturation is } 88 \% \text { or } \\
\text { lower }\end{array}$ & $\begin{array}{l}\text { For exacerbation } \\
\text { management }\end{array}$ \\
\hline
\end{tabular}

Abbreviations: COPD, chronic obstructive pulmonary disease; ICS, inhaled corticosteroid.

COPD. ${ }^{3,4,13}$ A pulmonary rehabilitation program can benefit patients with COPD by providing education and support to change behaviors, such as smoking cessation, improvement in nutrition, and adherence to the prescribed medication regimen ${ }^{61}$ Exercise training is a central component of pulmonary rehabilitation, which benefits patients by inducing changes in muscle biochemistry, resulting in improved muscle function. ${ }^{61}$ These changes delay the fatigue that is associated with lactic acidosis and enable patients to achieve enhanced exercise tolerance and consequential improvement in QoL. ${ }^{61}$ Exercise training also reduces dyspnea and increases expiratory time, thereby reducing dynamic hyperinflation. ${ }^{61}$ In addition, a recent review observed that pulmonary rehabilitation can increase motivation, self-efficacy for exercise, and functional capacity for physical activity, thereby enhancing activity and participation in extended activities of daily living. ${ }^{62}$

\section{The patient-centered medical home - a chronic care model for COPD}

Care for many patients with COPD is not optimal because it consists of rescue therapy during hospital visits for episodic exacerbations, with little or no treatment follow-up, rather than the recommended lifestyle change, long-term maintenance pharmacotherapy, and pulmonary rehabilitation. There is a need to move away from the rescue treatment approach toward a more patient-centric care model incorporating regular planned care. The chronic care model (CCM) provides a solution based on high-quality care focused on the following components. ${ }^{63}$

1. Enabling patient self-management by providing education, tools, motivation, and support to modify behaviors. Patients should be encouraged to be active participants in their medical care, tracking changes and reporting symptoms.

2. Establishing a practice team (ie, respiratory therapists, NPs, and PCPs), who give patients regular planned care and access to medical care, 24 hours a day, 7 days a week.

3. Implementing diagnostic and management guidelines that facilitate disease state management (eg, ATS/ERS, GOLD, NICE, or CTS) and provide continuity of care with referrals for comorbid conditions. The performance against guideline benchmarks should be assessed.

4. Applying population-based care and providing feedback to the clinical information systems (eg, registries).

Although there are limited data on the effectiveness of a CCM in COPD treatment, systematic reviews have shown that the model significantly reduces hospitalizations and the duration of emergency room visits when two or more of the above components are implemented. ${ }^{63,64}$ In addition to reducing health care utilization, application of a CCM to patients with COPD has also been shown to improve patients' QoL. ${ }^{65}$

The CCM suggestions for patients with COPD are aligned with the tenets of the patient-centered medical home (PCMH) (Figure 3), the principles of which were developed jointly by the American Academy of Family Practice, American College of Physicians, American Academy of Pediatrics, and American Osteopathic Association. ${ }^{66}$ 


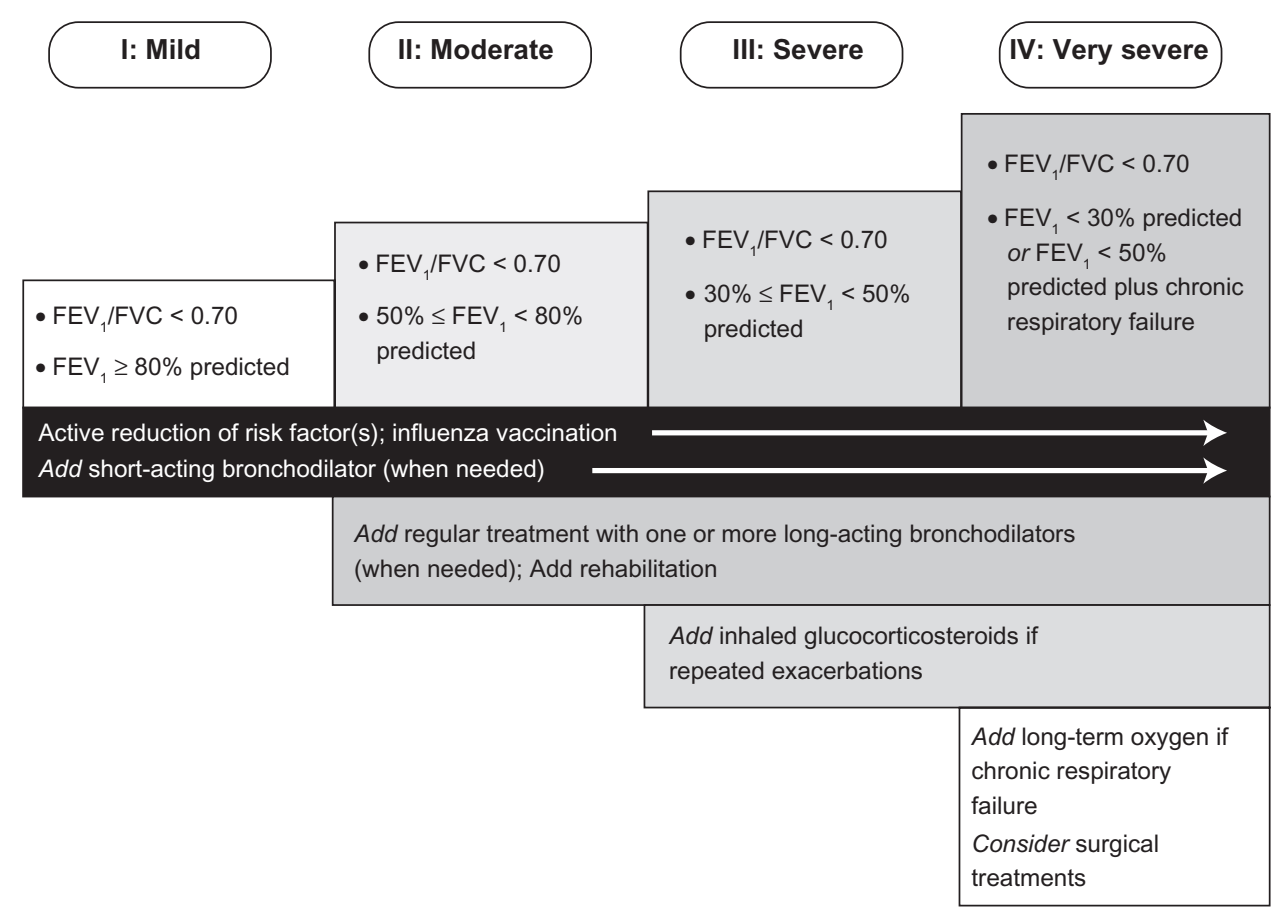

Figure 2 Therapy at progressing stages of chronic obstructive pulmonary disease. ${ }^{4}$

Note: From the Global Strategy for Diagnosis, Management and Prevention of COPD, updated 2010 used with permission from the Global Initiative for Chronic Obstructive Lung Disease (GOLD), www.goldcopd.org.

Abbreviations: $\mathrm{FEV}_{1}$, forced expiratory volume in I second; FVC, forced vital capacity.

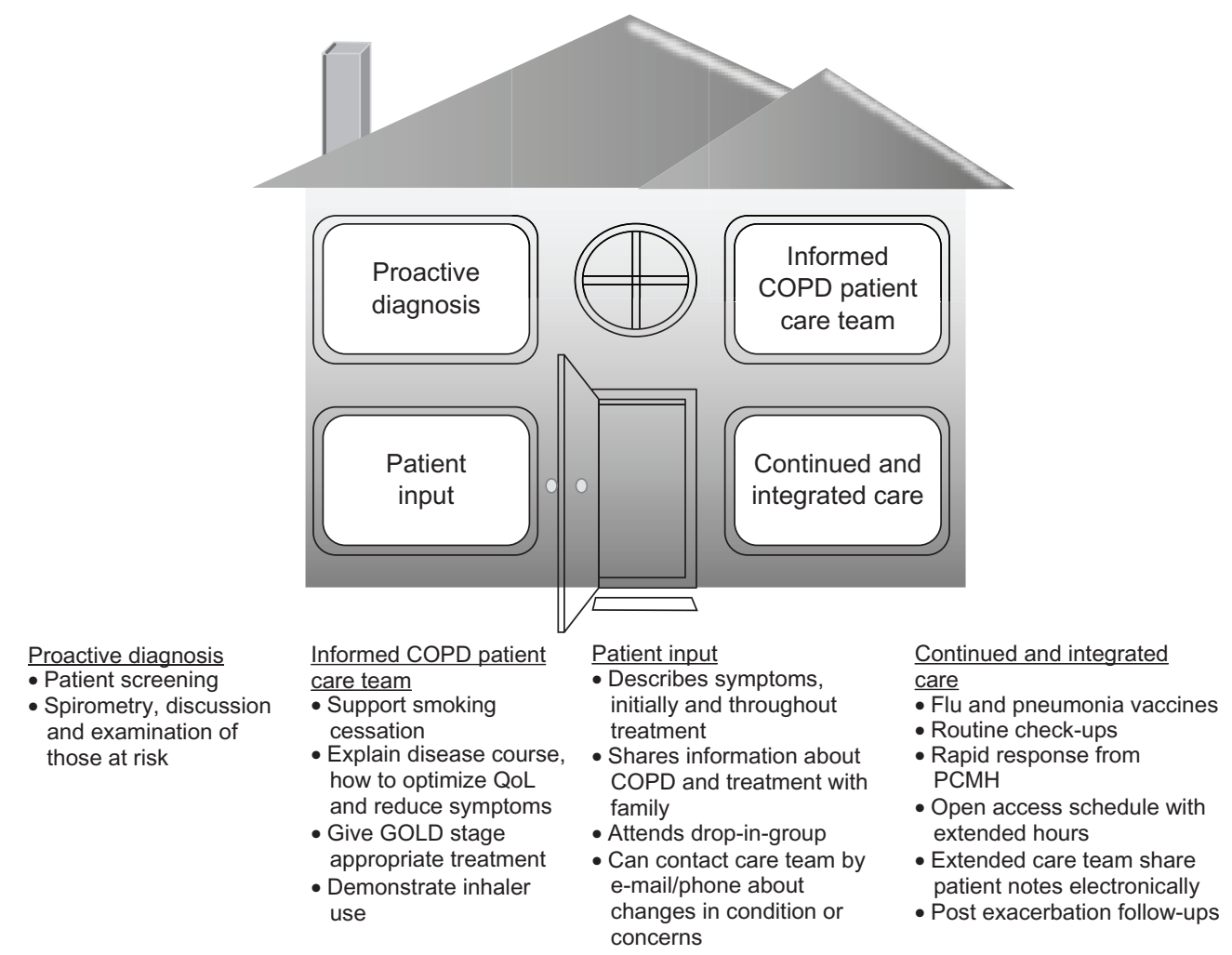

Figure 3 Chronic obstructive pulmonary disease care in a patient-centered medical home (PCMH).

Abbreviations: COPD, chronic obstructive pulmonary disease; GOLD, Global Initiative for Chronic Obstructive Lung Disease; QoL, quality of life; PCMH, patient-centered medical home. 
The PCMH is a refinement of and complement to the $\mathrm{CCM}^{67}$ and involves a multidisciplinary team that is focused on maintaining wellness rather than merely reacting to acute illness. ${ }^{66}$ The PCMH team is led by a PCP, who guides patient education, is the first point-of-care contact, and oversees continuous care. The core principles inherent to chronic COPD care practiced in a PCMH include proactive diagnosis, informed COPD patient care team, patient input, and continued and integrated care (Figure 3). Spirometry features prominently as part of the proactive diagnosis tenet. For instance, in managing a patient's care across different settings over time, a patient could be referred to a pulmonary function laboratory should the practice not have office spirometry or a pulmonologist available. Sharing of medical information via electronic means will also provide all the relevant health care providers with a patient's pulmonary function readings and other results needed to develop a long-term COPD management plan (eg, risk reduction measures, medication use, increasing physical activity) to improve whole patient care and long-term well-being. ${ }^{6}{ }^{6}$

A central feature of the PCMH is to consider the patient and all their comorbid conditions simultaneously, rather than focusing on just one disease in isolation. This approach is of particular relevance to the care of patients with COPD, who often have multiple comorbidities and resulting polypharmacy. To facilitate care, patients receive enhanced access to care when needed, while ensuring against overtreatment, and also receive extended hours and longer consultations with various team members as appropriate. In addition to traditional consultations, extended care can also include telephone and e-mail access or involvement in a specific patient group. All aspects of the PCMH should be monitored for quality and safety, to enable continual improvements to be made. ${ }^{69,70}$

Given the lack of research within the USA on the application and effectiveness of $\mathrm{CCM}$ and $\mathrm{PCMH}$ principles to COPD in the clinic, more research is needed on the clinical integration of evidence-based science in COPD.

\section{Conclusion}

Underdiagnosis and misdiagnosis of COPD leave patients with a reduced QoL and, potentially, a more rapidly progressing disease. In this respect, patients do not receive adequate care. Although guidelines and tools for the diagnosis of COPD are readily available, practitioner- and patient-related barriers can prevent an early diagnosis of this disease. Early diagnosis and management of COPD can improve long-term prognosis, giving patients the best opportunities to stop smoking, improve their QoL, reduce their symptoms, and reduce and delay both exacerbations and hospitalizations. To achieve earlier diagnosis and high standards of care for patients with COPD, improvements may be required at several levels within the health care system, including the utilization of patient care models such as the CCM and PCMH, and regular implementation of diagnosis and treatment guidelines by health care teams, together with provision of regular education and support to patients and their care providers.

\section{Acknowledgments}

The author acknowledges the editorial assistance of Radhika Bhatia, $\mathrm{PhD}$, of Envision Scientific Solutions in the development of the manuscript; editorial assistance was supported by Boehringer Ingelheim and Pfizer, Inc.

\section{Disclosure}

The author has received honoraria for speakers' bureau participation from Boehringer Ingelheim and Pfizer, Inc. The author exerted scientific control and is solely responsible for the content of the manuscript, having directed the manuscript's conceptual development and multiple rounds of substantive scientific revisions, and approved the final version for publication.

\section{References}

1. Eisner MD, Anthonisen N, Coultas D, et al. An official American Thoracic Society public policy statement: Novel risk factors and the global burden of chronic obstructive pulmonary disease. Am J Respir Crit Care Med. 2010;182(5):693-718.

2. Celli BR, MacNee W. Standards for the diagnosis and treatment of patients with COPD: a summary of the ATS/ERS position paper. Eur Respir J. 2004;23(6):932-946.

3. O'Donnell DE, Hernandez P, Kaplan A, et al. Canadian Thoracic Society recommendations for management of chronic obstructive pulmonary disease - 2008 update - highlights for primary care. Can Respir J. 2008;15 Suppl A:1A-8A.

4. Global Initiative for Chronic Obstructive Lung Disease (GOLD). Global strategy for the diagnosis, management and prevention of chronic obstructive pulmonary disease. December 2010. Available from: http:// www.goldcopd.org/uploads/users/files/GP:DReport_April112011.pdf. Accessed August 22, 2011.

5. National Clinical Guideline Centre. (2010) Chronic obstructive pulmonary disease: management of chronic obstructive pulmonary disease in adults in primary and secondary care. London: National Clinical Guideline Centre. Available from: http://guidance.nice.org.uk/CG101/ Guidance/pdf/English. Accessed August 22, 2011.

6. World Health Organization (WHO). Chronic obstructive pulmonary disease (COPD); Factsheet WHO/315. November 2006. Available from: http://whqlibdoc.who.int/fact_sheet/2007/FS_315.pdf. Accessed November 12, 2010.

7. Warren CP. The nature and causes of chronic obstructive pulmonary disease: a historical perspective. The Christie Lecture 2007, Chicago, USA. Can Respir J. 2009;16(1):13-20.

8. Ferrer M, Alonso J, Morera J, et al. Chronic obstructive pulmonary disease stage and health-related quality of life. The Quality of Life of Chronic Obstructive Pulmonary Disease Study Group. Ann Intern Med. 1997;127(12):1072-1079. 
9. Fletcher C, Peto R. The natural history of chronic airflow obstruction. Br Med J. 1977;1(6077):1645-1648.

10. Jones PW, Brusselle G, Dal Negro RW, et al. Health-related quality of life in patients by COPD severity within primary care in Europe. Respir Med. 2011;105(1):57-66.

11. Jones PW. Health status and the spiral of decline. COPD. 2009; 6(1):59-63.

12. Anthonisen NR, Skeans MA, Wise RA, Manfreda J, Kanner RE, Connett JE. The effects of a smoking cessation intervention on 14.5year mortality: a randomized clinical trial. Ann Intern Med. 2005; 142(4):233-239.

13. Marciniuk DD, Brooks D, Butcher S, et al. Optimizing pulmonary rehabilitation in chronic obstructive pulmonary disease-practical issues: a Canadian Thoracic Society Clinical Practice Guideline. Can Respir J. 2010;17(4):159-168.

14. Anzueto A. Primary care management of chronic obstructive pulmonary disease to reduce exacerbations and their consequences. Am J Med Sci. 2010;340(4):309-318.

15. Wise RA, Tashkin DP. Preventing chronic obstructive pulmonary disease: what is known and what needs to be done to make a difference to the patient? Am J Med. 2007;120(8 Suppl 1):S14-S22.

16. Yawn BP, Wollan PC. Knowledge and attitudes of family physicians coming to COPD continuing medical education. Int J Chron Obstruct Pulmon Dis. 2008;3(2):311-317.

17. Doherty DE, Briggs DD Jr. Chronic obstructive pulmonary disease: epidemiology, pathogenesis, disease course, and prognosis. Clin Cornerstone. 2004;Supp1 2:S5-S16.

18. Stratelis G, Jakobsson P, Molstad S, Zetterstrom O. Early detection of COPD in primary care: screening by invitation of smokers aged 40 to 55 years. Br J Gen Pract. 2004;54(500):201-206.

19. Walters JA, Hansen EC, Walters EH, Wood-Baker R. Under-diagnosis of chronic obstructive pulmonary disease: a qualitative study in primary care. Respir Med. 2008;102(5):738-743.

20. Radin A, Cote C. Primary care of the patient with chronic obstructive pulmonary disease-part 1: frontline prevention and early diagnosis. $\mathrm{Am}$ J Med. 2008;121(7 Suppl):S3-S12.

21. Bednarek M, Maciejewski J, Wozniak M, Kuca P, Zielinski J. Prevalence, severity and underdiagnosis of COPD in the primary care setting. Thorax. 2008;63(5):402-407.

22. Derom E, van Weel C, Liistro G, et al. Primary care spirometry. Eur Respir J. 2008;31(1):197-203.

23. Kaminsky DA, Marcy TW, Bachand M, Irvin CG. Knowledge and use of office spirometry for the detection of chronic obstructive pulmonary disease by primary care physicians. Respir Care. 2005;50(12):1639-1648.

24. Frank TL, Hazell ML, Linehan MF, Frank PI. The diagnostic accuracies of chronic obstructive pulmonary disease (COPD) in general practice: The results of the MAGIC (Manchester Airways Group Identifying COPD) study. Prim Care Respir J. 2006;15(5):286-293.

25. Moore PL. Practice management and chronic obstructive pulmonary disease in primary care. Am J Med. 2007;120(8 Suppl 1): S23-S27.

26. Foster JA, Yawn BP, Maziar A, Jenkins T, Rennard SI, Casebeer L. Enhancing COPD management in primary care settings. MedGenMed. 2007;9(3):24.

27. Damarla M, Celli BR, Mullerova HX, Pinto-Plata VM. Discrepancy in the use of confirmatory tests in patients hospitalized with the diagnosis of chronic obstructive pulmonary disease or congestive heart failure. Respir Care. 2006;51(10):1120-1124.

28. Bolton CE, Ionescu AA, Edwards PH, Faulkner TA, Edwards SM, Shale DJ. Attaining a correct diagnosis of COPD in general practice. Respir Med. 2005;99(4):493-500.

29. Tinkelman DG, Price DB, Nordyke RJ, Halbert RJ. Misdiagnosis of $\mathrm{COPD}$ and asthma in primary care patients 40 years of age and over. J Asthma. 2006;43(1):75-80.

30. Chapman KR, Tashkin DP, Pye DJ. Gender bias in the diagnosis of COPD. Chest. 2001;119(6):1691-1695.
31. Walker PP, Mitchell P, Diamantea F, Warburton CJ, Davies L. Effect of primary-care spirometry on the diagnosis and management of COPD. Eur Respir J. 2006;28(5):945-952.

32. Steel N, Maisey S, Clark A, Fleetcroft R, Howe A. Quality of clinical primary care and targeted incentive payments: an observational study. Br J Gen Pract. 2007;57(539):449-454.

33. Smith CJ, Gribbin J, Challen KB, Hubbard RB. The impact of the 2004 NICE guideline and 2003 General Medical Services contract on COPD in primary care in the UK. QJM. 2008;101(2):145-153.

34. Griffiths C, Feder G, Wedzicha J, Foster G, Livingstone A, Marlowe GS. Feasibility of spirometry and reversibility testing for the identification of patients with chronic obstructive pulmonary disease on asthma registers in general practice. Respir Med. 1999;93(12):903-908.

35. Halpin DM, Miravitlles M. Chronic obstructive pulmonary disease: the disease and its burden to society. Proc Am Thorac Soc. 2006;3(7):619-623.

36. Mapel DW, Frost FJ, Hurley JS, et al. An algorithm for the identification of undiagnosed COPD cases using administrative claims data. J Manag Care Pharm. 2006;12(6):457-465.

37. Briggs DD Jr. Chronic obstructive pulmonary disease overview: prevalence, pathogenesis, and treatment. J Manag Care Pharm. 2004;10(4 Suppl):S3-S10.

38. Decramer M, Cooper CB. Treatment of COPD: the sooner the better? Thorax. 2010;65(9):837-841.

39. Sundblad B-M, Larsson K, Nathell L. Low awareness of COPD among physicians. Clin Respir J. 2008;2(1):11-16.

40. Shahab L, Jarvis MJ, Britton J, West R. Prevalence, diagnosis and relation to tobacco dependence of chronic obstructive pulmonary disease in a nationally representative population sample. Thorax. 2006;61(12):1043-1047.

41. Celli BR. Chronic obstructive pulmonary disease: from unjustified nihilism to evidence-based optimism. Proc Am Thorac Soc. 2006;3(1):58-65.

42. Halliwell J, Mulcahy P, Buetow S, Bray Y, Coster G, Osman LM. GP discussion of prognosis with patients with severe chronic obstructive pulmonary disease: a qualitative study. $\mathrm{Br} J$ Gen Pract. 2004;54(509):904-908.

43. Pearson T, Kopin L. Bridging the treatment gap: improving compliance with lipid-modifying agents and therapeutic lifestyle changes. Prev Cardiol. 2003;6(4):204-211.

44. Anthonisen NR, Connett JE, Kiley JP, et al. Effects of smoking intervention and the use of an inhaled anticholinergic bronchodilator on the rate of decline of $\mathrm{FEV}_{1}$. The Lung Health Study. JAMA. 1994;272(19):1497-1505.

45. Deprez R, Kinner A, Millard P, Baggott L, Mellett J, Loo JL. Improving quality of care for patients with chronic obstructive pulmonary disease. Popul Health Manag. 2009;12(4):209-215.

46. Currie GP, Legge JS. ABC of chronic obstructive pulmonary disease. Diagnosis. BMJ. 2006;332(7552):1261-1263.

47. Celli BR, Halbert RJ, Nordyke RJ, Schau B. Airway obstruction in never smokers: results from the Third National Health and Nutrition Examination Survey. Am J Med. 2005;118(12):1364-1372.

48. Hanania NA, Mannino DM, Yawn BP, et al. Predicting risk of airflow obstruction in primary care: Validation of the lung function questionnaire (LFQ). Respir Med. 2010;104(8):1160-1170.

49. Yawn BP, Mapel DW, Mannino DM, Martinez FJ, Dalal AA. Performance of a brief, self-administered questionnaire (Lung Function Questionnaire) to identify patients at risk of airflow obstruction as potential candidates for spirometry: scoring and cut point [abstract]. Am J Respir Crit Care Med. 2009;179:A1476.

50. Mannino DM, Ford ES, Redd SC. Obstructive and restrictive lung disease and functional limitation: data from the Third National Health and Nutrition Examination. J Intern Med. 2003;254(6): 540-547.

51. Belfer MH. Office management of COPD in primary care: a 2009 clinical update. Postgrad Med. 2009;121(4):82-90. 
52. Sussman R. Part I: Identifying chronic obstructive pulmonary disease in patients with respiratory symptoms. Curr Med Res Opin. 2007;23 Suppl 3:S5-S12.

53. Barnes PJ. Mechanisms in COPD compared with asthma. Breathe. 2008;5(2):134-143.

54. Rabe KF, Hurd S, Anzueto A, et al. Global strategy for the diagnosis, management, and prevention of chronic obstructive pulmonary disease: GOLD executive summary. Am J Respir Crit Care Med. 2007; 176(6):532-555.

55. Yawn BP. Differential assessment and management of asthma vs chronic obstructive pulmonary disease. Medscape J Med. 2009;11(1):20.

56. British Thoracic Society, Scottish Intercollegiate Guidelines Network. British guideline on the management of asthma. Thorax. 2008;63 Suppl 4:iv1-iv121.

57. Dewar M, Curry RW Jr. Chronic obstructive pulmonary disease: diagnostic considerations. Am Fam Physician. 2006;73(4):669-676.

58. Ronchi MC, Piragino C, Rosi E, Amendola M, Duranti R, Scano G Role of sputum differential cell count in detecting airway inflammation in patients with chronic bronchial asthma or COPD. Thorax. 1996;51(10):1000-1004.

59. Hanania NA. The impact of inhaled corticosteroid and long-acting $\beta$-agonist combination therapy on outcomes in COPD. Pulm Pharmacol Ther. 2008;21(3):540-550.

60. Albert P, Calverley PM. Drugs (including oxygen) in severe COPD. Eur Respir J. 2008;31(5):1114-1124.

61. Casaburi R, ZuWallack R. Pulmonary rehabilitation for management of chronic obstructive pulmonary disease. $N$ Engl J Med. 2009;360(13):1329-1335.
62. ZuWallack RL. How do we increase activity and participation in our patients? Semin Respir Crit Care Med. 2009;30(6):708-712.

63. Adams SG, Smith PK, Allan PF, Anzueto A, Pugh JA, Cornell JE. Systematic review of the chronic care model in chronic obstructive pulmonary disease prevention and management. Arch Intern Med. 2007;167(6):551-561.

64. Steuten LM, Lemmens KM, Nieboer AP, Vrijhoef HJ. Identifying potentially cost effective chronic care programs for people with COPD. Int J Chron Obstruct Pulmon Dis. 2009;4(1):87-100.

65. Braman SS, Lee DW. Primary care management of chronic obstructive pulmonary disease: an integrated goal-directed approach. Curr Opin Pulm Med. 2010;16(2):83-88.

66. American Academy of Family Physicians. Joint principles of the PatientCentered Medical Home. Del Med J. 2008;80(1):21-22.

67. Wagner EH. Chronic disease management: what will it take to improve care for chronic illness? Eff Clin Pract. 1998;1(1):2-4.

68. Fromer L, Barnes T, Garvey C, Ortiz G, Saver DF, Yawn B. Innovations to achieve excellence in COPD diagnosis and treatment in primary care. Postgrad Med. 2010;122(5):150-164.

69. Patient Centered Primary Care Collaborative. Evidence of quality: evidence on the effectiveness of the Patient-Centered Medical Home on quality and cost [webpage on the Internet]. Washington, DC: PatientCentered Primary Care Collaborative; nd. Available from: http://www. pcpcc.net/content/evidence-quality. Accessed November 12, 2010.

70. Stange KC, Nutting PA, Miller WL, et al. Defining and measuring the patient-centered medical home. J Gen Intern Med. 2010;25(6): $601-612$.
International Journal of General Medicine

\section{Publish your work in this journal}

The International Journal of General Medicine is an international, peer-reviewed open-access journal that focuses on general and internal medicine, pathogenesis, epidemiology, diagnosis, monitoring and treatment protocols. The journal is characterized by the rapid reporting of reviews, original research and clinical studies across all disease areas.

\section{Dovepress}

A key focus is the elucidation of disease processes and management protocols resulting in improved outcomes for the patient.The manuscript management system is completely online and includes a very quick and fair peer-review system. Visit http://www.dovepress.com/ testimonials.php to read real quotes from published authors. 